\title{
PARTIAL BRIQUETTING vs DIRECT ADDITION OF BIOMASS IN COKING BLENDS
}

M.G. Montiano, E. Díaz-Faes, C. Barriocanal* Instituto Nacional del Carbón, INCAR-CSIC, Apartado 73, 33080 Oviedo. Spain

${ }^{*}$ Corresponding author. Tel: +34 9851190 90; Fax:+34 9852976 62; e.mail address: carmenbr@incar.csic.es

\section{ABSTRACT}

In this work partial briquetting is employed as a means of biomass densification to allow for biomass inclusion in coking coal blends. The effect of increasing the bulk density was evaluated by comparison with direct addition. Two briquettes of different composition were studied. The influence of the briquettes on the Gieseler plasticity of the coals was determined. It was found that the effect of the binder was not enough to compensate for the decrease in plasticity produced by the inert components of the briquettes. Carbonizations were carried out in a movable wall oven of $17 \mathrm{~kg}$ capacity and the quality of the cokes produced was tested by evaluating their mechanical strength, coke reactivity to $\mathrm{CO}_{2}$ and post-reaction strength. In addition, the porosity and ash chemistry of the cokes was determined and an attempt was made to establish a relation between these results and the quality of the cokes. Coke quality results suggest that $10-15 \mathrm{wt} \%$ of briquettes containing biomass can be included in coking blends.

Keywords: waste sawdust, coal, briquettes, coking, coke 


\section{Introduction}

There is general concern about the generation of greenhouse gases due to anthropogenic causes such as the use of fossil fuels. The steel industry is a major contributor to $\mathrm{CO}_{2}$ emissions because of its use of coal [1-3]. On the other hand, the international coal market has experienced considerable volatility in recent years, giving rise to a notorious variability in coal prices and problems related to supply.

The use of additives is a common practice in cokemaking in the search for alternative materials with which to make low-cost coking blends and to improve the coking characteristics of a specific coal blend [4-8]. With these considerations in mind the inclusion of biomass in coking blends has been the subject of a number of recent studies [9-12].

The co-carbonization of coal blends with additives has been observed to modify the coking properties of coals and the quality of the resulting cokes significantly $[5,13]$. In the present work, the effects of adding alternative raw materials to coking coals have been assessed. The possibility of including materials different from coking coals in coke ovens is of great interest because of the lower cost of these materials and also as a way to overcome the problems related to the shortage of coking coals. In view of the immense importance of the plastic stage on the properties of the final coke, the effect of biomass on coal plastic properties has been investigated by high-temperature small-amplitude oscillatory-shear (SAOS) rheometry and Gieseler plasticity test to determine whether the use of a specific biomass can produce a reduction in coal plastic properties [10, 14].

Some research works have already been published on the inclusion of biomass in coking blends $[1,11,12]$ but to our knowledge this is the first study on the use of partial briquetting to allow the inclusion of biomass in coking blends. The procedure is based a combination of two factors: 1 . increasing the bulk density of the charge and 2 . using the binder present in the briquettes to restore the coal's plastic properties.

It is generally recognized that coke reactivity and post-reaction strength are the parameters that should be used to determine coke quality. Therefore a study of the reactivity of the biomass will contribute greatly to assess the effect of using biomass as additive on the 
quality of the coke produced. Biomass-derived chars are more reactive than coal chars. This higher reactivity is thought to derive from their porous structure and the presence of inherent catalytic elements such as $\mathrm{K}$ that have a strong catalytic effect [15-18]. When using a highly reactive coke in a blast furnace it is important to bear in mind that lowering the temperature of the thermal reserve zone will decrease the $\mathrm{CO} / \mathrm{CO}_{2}$ ratio and increase the gas utilization ratio. This will result in a lower reducing agent rate which is considered to be an effective method for decreasing the emission of carbon dioxide in steel works [19, 20]

The aim of the present work is to study the effect of addition of biomass on the quality of the coke produced from two coking coals of different quality. The effect of densifying the charge on the quality of the coke produced by adding briquettes was compared with the effect of direct addition of the briquette components.

\section{Experimental}

\subsection{Materials and methods}

Waste chestnut sawdust (SC1), a non-coking coal of high rank (K) normally used as pulverized injection coal $(\mathrm{K})$, two coking coals $(\mathrm{P}$ and $\mathrm{M})$ and coal tar $(\mathrm{T})$ were selected as materials for the experiments. Briquettes were prepared by using a roller press consisting of two rollers rotating in opposite directions at the same speed [21]. The material was squeezed through the gaps between the two rollers. The briquettes obtained had an ellipsoidal shape, with 46 and $42 \mathrm{~mm}$ long axes and a weight of around $23 \mathrm{~g}$. Two briquettes with different compositions were produced: B1 and B2. A diagram of the procedure used for making briquettes is presented in Figure 1.

Proximate analyses were performed following the ISO562 and ISO1171 standard procedures for the volatile matter and ash content, respectively. An elemental analysis was carried out using a LECO CHN-2000 for C, H and N, a LECO S-144 DR for sulphur and a LECO VTF-900 for the direct determination of oxygen. The inorganic matter composition of each sample was analysed by X-Ray fluorescence (XRF) in a SRS 3000 Bruker spectrometer in accordance with the ASTM D4326-04 standard procedure. 


\subsection{Assessment of coal thermoplastic properties}

The thermoplastic properties of the base coal and of the blends containing 2, 5, 10 and $15 \mathrm{wt} \%$ of each briquette were measured by means of the Gieseler test (ASTM D263974). The Gieseler fluidity of the briquettes was also measured. A $5 \mathrm{~g}$ sample with a size < $0.425 \mathrm{~mm}$ was heated while a constant torque was applied to a stirrer placed in the crucible containing the coal charge. The parameters measured by this test were: (i) softening temperature, Ts; (ii) the temperature of maximum fluidity, Tf; (iii) resolidification temperature, Tr; (iv) plastic range, Tr-Ts, which is defined as the difference between the resolidification and softening temperatures; and (v) maximum fluidity, MF, expressed as dial divisions per minute (ddpm).

\subsection{Carbonization experiments and coke quality evaluation}

Carbonization tests were carried out in a movable wall oven of approximately $17 \mathrm{~kg}$ capacity (MWO17) [8]. The dimensions of the oven are $250 \mathrm{~mm} \mathrm{~L} \times 165 \mathrm{~mm} \mathrm{~W} \times 790 \mathrm{~mm} \mathrm{H}$. A load cell was mounted on the movable wall to measure the force exerted on the wall during carbonization. A programmable controller was used to control the oven temperature. The temperature at the centre of the coal charge was monitored by means of a thermocouple connected to a computer. The coal was charged when the oven had reached $1100^{\circ} \mathrm{C}$. The temperature of the wall was kept constant throughout the test. The coke was pushed out 15 min after the centre of the charge had reached $950{ }^{\circ} \mathrm{C}$. The coking time lasted approximately 3.5 hours. The moisture of the charge was fixed at $5 \mathrm{wt} \%$. The carbonizations were carried out in two ways: 1 . by means of a partial briquetting procedure in which a mixture of the coal and a percentage of the briquettes was carbonized in the carbonization oven and 2. by direct addition where a mixture of the coal and the corresponding percentages of briquette components (binder, biomass, non-coking coal, coking coal) were directly added. Special care was taken with direct addition to ensure the homogeneity of the mixture to be carbonized. The following nomenclature was used: B1 and B2 represent partial briquetting procedure and B1D and B2D direct addition of the components of briquettes B1 and B2 respectively. 
The cold mechanical strength of the cokes produced was assessed by the JIS test (JIS K2151 standard procedure). After the test the coke was sieved and the DI150/15 index was calculated from the amount of coke with a particle size greater than $15 \mathrm{~mm}$. The coke reactivity and mechanical strength after reaction were assessed by means of the NSC test (ASTM D5341 standard procedure). Two indices were derived from this test i.e. the CRI index which represents the loss of weight of a $200 \mathrm{~g}$ sample of coke with size between 19$22.4 \mathrm{~mm}$ after reaction with $\mathrm{CO}_{2}$ at $1100{ }^{\circ} \mathrm{C}$ for two hours and the CSR index which represents the percentage of partially-reacted coke that remains on the $9.5 \mathrm{~mm}$ sieve after 600 revolutions in a standardized drum. The relationship between the CSR values obtained in a MWO of $17 \mathrm{~kg}$ capacity and those obtained in a MWO of $300 \mathrm{~kg}$ has been published recently [22].

\subsection{Determination of the porous structure of the cokes}

The true density $\left(\rho_{\mathrm{He}}\right)$ of the cokes was measured by means of helium pycnometry in a Micromeritics Accupyc 1330 Pycnometer. Their apparent density $\left(\rho_{\mathrm{Ap}}\right)$ was determined with $\mathrm{Hg}\left(\rho_{\mathrm{Hg}}\right)$ using coke samples with a particle size between 1-3 mm, and water $\left(\rho_{\mathrm{H} 2 \mathrm{O}}\right)$. The $\rho_{\mathrm{H} 2 \mathrm{O}}$ was determined by water displacement using a $300 \mathrm{~g}$ coke sample with a particle size of $19-22.4 \mathrm{~mm}$. From the true and apparent densities, the open porosity was calculated by means of the following equation:

$$
\varepsilon(\%)=\left(1-\frac{\rho_{A p}\left(\mathrm{~g} / \mathrm{cm}^{3}\right)}{\rho_{H e}\left(\mathrm{~g} / \mathrm{cm}^{3}\right)}\right) \cdot 100
$$

\section{Results and discussion}

\subsection{Characteristics of materials used}

The results of the proximate and elemental analyses of the raw materials have been included in Table 1. The base coals $\mathrm{P}$ and $\mathrm{M}$ have a volatile matter content of 22.7 and 24.5 $w t \% d b$ respectively and an ash content of around $8 w t \% d b$. The sawdust (SC1) presents a high volatile matter content but a low ash and negligible sulphur content. The $\mathrm{PCl}$ coal $(\mathrm{K})$ has a low volatile matter content and sulphur and ash contents similar to that of the base 
coal. The $\mathrm{C} / \mathrm{H}$ and $\mathrm{C} / \mathrm{O}$ atomic ratio is low for sawdust due respectively to its low carbon content and high oxygen content. The composition of the briquettes appears in Table 2 along with the amount of the briquette components that each percentage of briquettes represents in the whole blend. These percentages were used for the tests carried out with direct addition. B1 contains 15 wt. \% sawdust, 70 wt. \% PCl coal and binder (T) while B2 contains half of the amount of the $\mathrm{PCl}$ coal. The non-coking coal $(\mathrm{K})$ was replaced by coking coal $\mathrm{P}$ to determine the effect of including a smaller amount of alternative raw materials in the briquettes. An increase in the percentage of B1 from 2 to 15 wt. \% represents an increase of 0.3 to $2.25 \mathrm{wt} \%$ in the amount of tar and sawdust whereas the $\mathrm{PCl}$ coal increases from 1.4 to 10.5 wt. \%. In the case of B2, the amount of SC1 and binder is the same as in the previous case except that the percentage of coal $\mathrm{K}$ in the blend is higher: $5.25 \mathrm{wt} . \%$. The purpose of including coking coal in the formulation of briquette B2 was to determine whether the presence of a coal with thermoplastic properties would facilitate the incorporation of the sawdust within the coke matrix. Tar was used not only as binder for the preparation of the briquettes but also because its plasticizing characteristics would contribute to a better integration of the sawdust within the structure of the coke.

\subsection{Variation of the thermoplastic properties of the coal due to the addition of}

\section{briquettes}

Coking coals go through a plastic stage between 400 and $500{ }^{\circ} \mathrm{C}$ during heating in the absence of air with the result that the particulate matter becomes a coherent mass of semicoke that on further heating will be converted into coke. Generally speaking, plasticity increases with decreasing rank and reaches a maximum in coals with a volatile matter content between 32 and 34 wt\% at which point it then decreases sharply. Plasticity as measured by the Gieseler test occurs in coals with a volatile matter content between 15 and $34 \mathrm{wt} \% \mathrm{db}[5,23]$. This behaviour is related to the cross-link density and size of the planar macro-molecules which constitute the coals. In other words, for low-rank coals the presence of oxygen cross-links prevents fusion. With increasing rank, these types of bonds are replaced by $\mathrm{H}$ bonds, which are weaker and so the coals start to fuse on heating. In the case 
of higher rank coals, the aromaticity increases along with the macromolecular size and covalent cross-linkages which in turn lead to a decrease in fluidity [23-25]. This property is essential for the development of the structure and properties of cokes and for this reason the influence of briquettes on this coal property has been the subject of study in the present work. Figure 2 shows curves obtained for the two coals and the addition of 2, 5, 10 and 15 wt $\%$ of briquettes B1 and B2. It can be seen that the maximum fluidity of the blends decreases to around $50 \%$ as the amount of briquettes increases to $15 \mathrm{wt} \%$. These results can be explained by the effect of components of the briquettes, although Gieseler fluidity is not an additive property. The effect of additives of various origins on Gieseler plasticity has already been reported in the literature $[5,10,13,14,26]$. Plasticizing additives such as coal tar or coal tar pitch produce an increase in fluidity of the coal while infusible material and biomass tend to decrease the thermoplastic properties of a coal. The briquettes prepared in this research work are constituted of: biomass, coking coal, non-coking coal and tar. Consequently, materials that influence coal plasticity both positively and negatively are present. In the case of B1 the only contribution towards an increase in plasticity is the binder, whereas B2 contains coking-coal apart from the binder. Consequently the reduction in coal fluidity is greater when B1 is added than when B2 is included ( $58 \%$ vs $55 \%$ for base coal $P$ and $68 \%$ vs $54 \%$ for base coal M). No great effect was observed on the plastic range of the coal upon the addition of briquettes (Table 3). Infusible materials, such as non-coking coal tend to reduce the plastic range because of the increase in softening temperature $[13,26]$. In contrast, addition of asphalts, pitches or tars lowers the softening temperature, but the resolidification temperature does not change, and so the plastic range increases [26, 27]. Addition of sawdust does not entail a significant variation in the plastic range [10]. Plasticity of the briquettes was tested to determine whether any of them showed any fluidity. It was found that none of them showed plasticity including B2, which contained coking coal.

\subsection{Carbonization tests in a movable wall oven of $17 \mathrm{~kg}$}

In order to study the effect of densification of biomass when a partial briquetting procedure is employed, carbonizations tests with partial briquetting and direct addition were 
carried out in an oven of $17 \mathrm{~kg}$ capacity. One of the problems associated with the use of biomass is its low bulk density. At the same time, bulk density of the charge is considered an important factor for controlling the coking process because of its influence on the yield, the quality of the product and operational problems such as the generation of excessive coking pressure. The bulk density of a coal charge using a top charging procedure depends on the moisture and particle size of the coal. Table 4 presents the particle size for the base coals $\mathrm{P}$ and $\mathrm{M}$ and for the materials employed in the preparation of the briquettes. Sawdust has the finest particle size distribution with $97 \mathrm{wt} \%$ smaller than $3 \mathrm{~mm}$ and $86 \mathrm{wt} \%$ smaller than 0.5 $\mathrm{mm}$. The non-coking coal $(\mathrm{K})$ has around $90 \mathrm{wt} \%$ that is smaller than $3 \mathrm{~mm}$ but only $35 \mathrm{wt} \%$ smaller than $0.5 \mathrm{~mm}$. In a previous research work the effect of direct addition of sawdust on the bulk density of the coal charge in a coking oven was studied to find out whether even a low percentage of sawdust produced a reduction in bulk density [12]. The data in Figure 3 show the variation in bulk density with increasing amounts of briquettes B1 and B2 and allow the partial briquetting procedure to be compared with that of direct addition in relation to the effect on the bulk density of the charge. Carbonization of the base coal $(P)$ alone was carried out using a bulk density of $776 \mathrm{~kg} / \mathrm{m}^{3}$. For all the percentages tested, partial briquetting produced an increase in bulk density compared to that of the base coal, whereas direct addition resulted in a bulk density which was lower than that of the base coal carbonized on its own. Increasing the amount of briquettes in the blend produced a gradual increase in the bulk density of the charge. The highest value was obtained for $10 \mathrm{wt} \%$ addition. No differences were observed in the effects the two briquettes had on bulk density, possibly due to the fact that both briquettes contain the same amount of biomass.

A coke intended for use in the blast furnace must maintain a strict level of quality in terms of mechanical strength and reactivity to $\mathrm{CO}_{2}$. The variation in the mechanical strength index DI150/15 with the amount of briquettes in the charge is shown in Figure 4 where the four lines correspond to the addition of briquettes B1 and B2 to coals $\mathrm{P}$ and $\mathrm{M}$. For the same coking coal it can be seen that, as the percentage of briquettes increases the difference between the mechanical strengths of the cokes produced with the addition of either briquette 
(B1 and B2) also increases. The strength of the cokes is in all cases greater when B2 is added than with the addition of B1 for the same base coal. The presence of the coking coal in the briquettes contributes to the integration of the sawdust within the coke matrix. In the case of B2 there is almost no variation in the strength of the coke compared to the base coal up to $15 \mathrm{wt} \%$ addition, especially in the case of coal P. The DI150/15 index of the coke from coal $P$ is 76 whereas in the case of the addition of $15 w t \%$ of $B 2$ the index is 78 . In the case of coal M the coke produced without any addition has an DI150/15 index of around 77, whereas with $15 \mathrm{wt} \%$ addition of B2 the DI150/15 index is around 74. Differences of 5 points do not represent differences in quality for DI150/15 values between 70 and 80 . To be able to compare partial briquetting with direct addition in Figure $5 a$ for B1 and in Figure $5 b$ for B2 the mechanical strength indices of the cokes produced using both procedures can be compared. Two factors need to be taken into consideration. With partial briquetting there is an increase in bulk density which should be reflected in the enhancement of the quality of the coke. At the same time the additives (sawdust, tar and non-coking coal) are present in small pockets in the charge so that the binder will compensate for any decrease in plasticity that may be caused by the additives, although the particles of coking coal surrounding the particles of sawdust will be fewer than in the case of direct addition. As a consequence more fissures will be created and the integration of the sawdust within coke matrix will be undermined. In the case of B1 (with no coking coal) for low percentages of addition, the mechanical strength is higher for cokes produced with partial briquetting but in the case base coal $\mathrm{P}$ for addition percentages higher than $10 \%$ the mechanical strength of the coke with direct addition is better than with partial briquetting. Consequently for $10 \mathrm{wt} \%$ addition the second factor appears to be more important. In the case of briquette B2 which contains coking coal (Figure $5 b)$ the mechanical strength of the cokes produced from $\mathrm{P}$ with partial briquetting are higher than with direct addition. To ensure the mechanical strength of the coke produced by adding between 10 and $15 w t \%$ of briquettes that do not contain coking coal (B1) the best method of adding sawdust is by direct addition. On the other hand in the case of B2 the mechanical strength of the cokes is always higher when partial briquetting is used. The inclusion of 
coking coal in the formulation of the briquettes produces cokes with greater mechanical strength.

The most widely used procedure for testing coke quality is to measure the reactivity to $\mathrm{CO}_{2}(\mathrm{CRI}$ index) and the post-reaction strength (CSR index). Coke reactivity depends mainly on the characteristics of the raw materials. Consequently coal rank and ash chemistry are the most important parameters that will determine the reactivity of a coke. In the present work coke reactivity was measured in order to assess the effect of biomass addition and the effectiveness of the procedure used. Figure 6 shows the variation in the CRI and CSR values of the cokes produced with the addition of increasing amounts of briquettes B1 and B2 for the two coals tested i.e. P and M. In this way it was possible to assess the effect of including a coking coal in the composition of the briquettes. The base cokes show similar cold mechanical strength characteristics but different reactivities to $\mathrm{CO}_{2}$ and post-reaction strengths. Whereas coal P produces a coke of poor quality, coal M produces a good quality coke. The results obtained do not reveal significant differences in the CRI and CSR indices obtained for the cokes produced with the addition of the two briquettes. In the case of coal P it is possible to include up to $15 \mathrm{wt} \%$ of either type of briquette without causing any significant impairment of the CRI and CSR indices. In the case of coal M the impairment is more pronounced specially when $15 \mathrm{wt} \%$ is added. To be able to compare the effect of the two addition procedures -i.e. direct addition and partial briquetting - Figure 7 shows the CSR results of the cokes produced by these two methods. Partial briquetting causes an increase in the bulk density of the charge (Figure 3 ) and it is well known that increasing the bulk density of a charge in the coking oven is related to increases in the CSR of the coke produced. Our results show that in this case the CSR values of the cokes produced from partial briquetting are in every case higher than those produced by direct addition. Contrary to the results obtained for the mechanical strength which indicated that for percentages greater than $10 \mathrm{wt} \%$ addition the results are better with direct addition, in this case the influence of the increase in the bulk density of the charge overrides the effect of the distribution of the biomass within the coking charge. Generally speaking, the main factors 
that influence the quality of the cokes produced due to the presence of additives can be summarized as follows: 1 . modification of the coal plastic stage, which is the most important phase during the coking process and determines the structure of the product and 2. effect on the ash chemistry of the cokes. The porous characteristics of the cokes prepared with coal P as base have been included in Table 5. In general, for the same level of addition partial briquetting produces cokes with a lower total porosity as a consequence of the higher bulk density during coking. In a previous research paper [12] it was found that the addition of sawdust to an industrial coal blend gave rise to cokes with a higher total porosity, although no relationship was established between the data obtained from the mechanical strength drum test and porosity determinations. Nevertheless, it is evident that, pores are the places where microfissures form and then develop into flaws [28].

In contrast, the porosity corresponding to pore sizes lower than $12 \mu \mathrm{m}$ is not as extended in cokes produced with direct addition. The results shown in Figure 5 indicate that for additions higher than $10 \mathrm{wt} \%$, direct addition produces cokes with better mechanical strength. This could be related to the results obtained for the porosity corresponding to sizes lower than $12 \mu \mathrm{m}$ supporting the explanation proposed above that with the presence of a certain amount of sawdust in the coking blend, the resulting closer contact of the sawdust with the coking coal allows it to be more easily integrated within the coke matrix, reducing the number of microfissures that might otherwise develop into fractures.

Another important factor that may have an effect on the quality of the cokes produced with additives is the modification of the coke ash chemistry due to the catalytic effects of metals such as $\mathrm{Fe}, \mathrm{Ca}, \mathrm{K}, \mathrm{Na}$ or $\mathrm{Mg}$. To take into consideration the ash chemistry, models used to predict coke strength after reaction include, among other factors such as plasticity and maceral composition, a alkalinity index $(\mathrm{Al})$ being the ratio between the basic oxides and acidic oxides [1, 29] :

$$
A I=A s h \cdot\left(\frac{F e 2 O 3+C a O+N a 2 O+K 2 O+M g O}{A l 2 O 3+S i O 2}\right)
$$


An analysis of the composition of the ash is presented in Table 6. From these values, the alkalinity index was calculated. It was found that the CSR of the corresponding cokes were linearly correlated to the Al with a correlation coefficient of $r=0.893$.

In view of the results presented in a previous paper [10] it appears that the addition of sawdust in the form of briquettes gives rise to cokes of better quality than when only sawdust is included in the coking blend. This enhances the role of the binder that may help to restore the loss of fluidity produced by the sawdust and the increase of bulk density produced by the addition of sawdust in the form of briquettes.

The two coals chosen presented similar volatile matter contents but produced cokes of different quality, especially with respect to coke reactivity to $\mathrm{CO}_{2}$ (CRI and CSR indices). Whereas coal $\mathrm{P}$ produced a coke of low quality, coal $\mathrm{M}$ gave rise to a coke which could be used in most blast furnaces. It is apparent from the results that the base coal used for the additions is of great importance considering the different behaviours of the two coals selected. It might therefore be of interest to study the use of a complex industrial blend as base. Some questions still remain to be answered such as the importance of the size of the briquettes which may affect the distribution of the biomass within the coal mass.

\section{Conclusions}

1. Direct addition produces a decrease in the bulk density of the charge which does not occur with partial briquetting.

2. The mechanical strength of cokes produced was better when briquettes were used, except in the case of 10 and $15 \mathrm{wt} \%$ addition of B1 due to a better distribution of sawdust within the coal mass resulting in a more effective interaction between sawdust and coking coal.

3. With respect to coke reactivity it would be possible to add up to $15 \mathrm{wt} \%$ of briquettes without impairing coke quality in the case of coal P. However, the amount should not exceed $10 \mathrm{wt} \%$ in the case of coal M.

4. The total porosity is lower in cokes produced by partial briquetting due to the increase in bulk density. 


\section{Acknowledgements}

The research leading to these results has received funding from the European Union's Research Programme of the Research Fund for Coal and Steel (RFCS) research programme under grant agreement No. [RFCR-CT-2010-00007]. M.G.M. thanks the Government of the Principado de Asturias for the award of a pre-doctoral grant with funds from the PCTIAsturias within the Severo Ochoa program. 


\section{References}

1. Ng KW, MacPhee JA, Giroux L, Todoschuk T. Reactivity of bio-coke with $\mathrm{CO}_{2}$. Fuel Process Technol 2011; 92: 801-804.

2. Carpenter A. $\mathrm{CO}_{2}$ abatement in the iron and steel industry. IEA Clean Coal Centre; 2012.

3. Norgate T, Haque N, Somerville M, Jahanshahi S. Biomass as a source of renewable carbon for iron and steelmaking. ISIJ Int 2012; 52: 1472-1481.

4. Patrick JW, Stacey AE. The strength of industrial cokes. 7. Further studies of the influence of additives in a coke-oven charge on the tensile strength of coke. Fuel 1978; 57 258-264.

5. Loison R, Foch P, Boyer A (Eds.) Coke Quality and Production. Butterworths, London 1989.

6. Menéndez JA, Pis JJ, Álvarez R, Barriocanal C, Canga CS, Fuente E, Díez MA. Characterization of petroleum coke as additive in metallurgical cokemaking. Influence on metallurgical coke quality. Energ Fuel 1997; 11: 379-384.

7. Barranco R, Patrick JW, Snape C, Thompson A. Impact of low-cost filler material on coke quality. Fuel 2007; 86: 2179-2185.

8. Fernández AM, Barriocanal $C$, Alvarez R. The effect of additives on coking pressure and coke quality. Fuel 2012; 95: 642-647.

9. MacPhee JA, Gransden JF, Giroux L, Price JT. Possible CO2 mitigation via addition of charcoal to coking coal blends. Fuel Process Technol 2009; 90:16-20.

10. Montiano MG, Barriocanal C, Alvarez R. Effect of the addition of waste sawdust on thermoplastic properties of a coal. Fuel 2013; 106: 537-543.

11. Kokonya S, Castro-Díaz M, Barriocanal C, Snape CE. An investigation into the effect of fast heating on fluidity development and coke quality for blends of coal and biomass. Biomass Bioenerg 2013; 56: 295-306.

12. Montiano MG, Díaz-Faes E, Barriocanal C, Alvarez R. Influence of biomass on metallurgical coke quality. Fuel 2014; 116: 175-182.

13. Fernández AM, Barriocanal C, Díez MA, Álvarez R. Influence of the additives of various origins on thermoplastic properties of coal. Fuel 2009; 88: 2365-2372.

14. Castro-Díaz M, Zhao H, Kokonya S, Dufour A, Snape CE. The effect of biomass on fluidity development in coking blends using high-temperature SAOS rheometry. Energ Fuel 2012; 26: 1767-1775.

15. Vassilev SV, Baxter D, Andersen LK, Vassileva CG. An overview of the chemical composition of biomass. Fuel 2010; 89: 913-933.

16. Dupont C, Nocquet Te, Da Costa Jr JA, Verne-Tournon Cl. Kinetic modelling of steam gasification of various woody biomass chars: Influence of inorganic elements. Bioresour Technol 2011; 102: 9743-9748. 
17. Risnes H, Fjellerup J, Henriksen U, Moilanen A, Norby P, Papadakis K, Posselt D, SÃrensen L. Calcium addition in straw gasification. Fuel 2003; 82: 641-651.

18. Lahijani P, Zainal ZA, Mohamed AR, Mohammadi M. CO2 gasification reactivity of biomass char: Catalytic influence of alkali, alkaline earth and transition metal salts. Bioresource Technol 2013; 144: 288-295.

19. Ariyama T, Murai R, Ishii J, Sato M. Reduction of CO2 Emissions from Integrated Steel Works and Its Subjects for a Future Study. ISIJ Int 2005; 45: 1371-1378.

20. Ueda S, Watanabe K, Inque R, Ariyama T. Catalytic effect of $\mathrm{Fe}, \mathrm{CaO}$ and molten oxide on the gasification reaction of coke and biomass char. ISIJ int 2011; 51: 1262-1268.

21. Álvarez R, Barriocanal C, Díez MA, Cimadevilla JLG, Casal MD, Canga CS. Recycling of hazardous waste materials in the coking process. Environ Sci Technol 2004; 38: 16111615.

22. Díaz-Faes E, Álvarez R, Barriocanal C, Díez MA. Semi-pilot scale carbonization to assess blast furnace coke quality. In: Proc ICCS\&T 2011. Oviedo 2011 P1.20.

23. Marsh $\mathrm{H}$. The cokemaking process. Proc Ironmaking Conference, Toronto, Canada, 1992, Vol. 51: 569-580.

24. Butterfield IM, Thomas KM. Some aspects of changes in the macromolecular structure of coals in relation to thermoplastic properties. Fuel 1995; 74: 1780-1785.

25. Nomura S, Thomas KM. Fundamental aspects of coal structural changes in the thermoplastic phase. Fuel 1998; 77: 829-836.

26. Haberbehl D, Orywal F, Beyer HD. Plastic properties of coal. In: Elliot MA (Ed) Chemistry of Coal Utilization, $2^{\text {nd }}$ supplementary volume Wiley, interscience, New York; 1981.

27. Sakurovs R, Lynch LJ. Direct observations on the interaction of coals with pitches and organic compounds during co-pyrolysis. Fuel 1993; 72: 743-749.

28. Patrick JW, Walker A. Porosity and strength of carbon materials. In: Patrick JW (Ed.) Porosity in carbons: characterization and applications. Edward Arnold 1995.

29. Díez MA, Alvarez R, Barriocanal C. Coal for metallurgical coke production: predictions of coke quality and future requirements for cokemaking. Int J Coal Geol 2002; 50: 389-412. 


\section{Figure Captions}

Figure 1. Diagram of the procedure used to produce briquettes and photograph of briquettes obtained.

Figure 2. Gieseler fluidity curves of coal $\mathrm{P}$ and $\mathrm{M}$ with addition of various amounts of briquettes $\mathrm{B} 1$ and $\mathrm{B} 2$.

Figure 3. Variation of bulk density of the charge due to partial briquetting. Coal P.

Figure 4. Influence of briquette addition on coke mechanical strength.

Figure 5. Comparison between mechanical strength of cokes produced with direct addition and partial briquetting.

Figure 6. Effect of composition of briquettes on CRI and CSR indices of cokes from coals P and $\mathrm{M}$ with the addition of briquettes $\mathrm{B} 1$ and $\mathrm{B} 2$.

Figure 7. Effect of densification on the quality of cokes produced. 
Table 1. Proximate and ultimate analysis of the materials.

\begin{tabular}{lccccc}
\hline & P & M & SC1 & K & Tar \\
\hline VM (wt.\% db) & 22.7 & 24.5 & 78.8 & 14.6 & $65.9^{3}$ \\
Ash (wt.\%db) & 7.8 & 7.5 & 1.3 & 8.4 & -- \\
C (wt.\%db) & 83.7 & 82.5 & 50.2 & 83.0 & 90.3 \\
H (wt.\%db) & 4.8 & 4.6 & 5.7 & 3.9 & 4.7 \\
N (wt.\%db) & 1.5 & 1.4 & 0.5 & 2.1 & 0.8 \\
S (wt.\%db) & 0.75 & 0.72 & 0.00 & 0.48 & 0.38 \\
$\mathrm{O}($ wt.\%db) & 2.6 & 3.0 & 43.0 & 2.6 & 2.8 \\
$\mathrm{C} / \mathrm{H}^{2}$ & 1.5 & 1.5 & 0.7 & 1.8 & 1.6 \\
$\mathrm{C} / \mathrm{O}^{2}$ & 42.9 & 33.3 & 1.6 & 42.6 & 43.0 \\
\hline
\end{tabular}

${ }^{1} \mathrm{VM}$, volatile matter content on a dry basis $(\mathrm{db}){ }^{2}$ Atomic ratio. 3: From thermogravimetric analysis. 
Table 2. Composition of briquettes and percentage of each component present in blends of the base coal with briquettes.

\begin{tabular}{lccccc}
\hline & $P(w t . \%)$ & M (wt.\%) & SC1 (wt.\%) & K (wt.\%) & Tar (wt.\%) \\
\hline B1 & 0.00 & -- & 15.00 & 70.00 & 15.00 \\
B2 & 35.00 & -- & 15.00 & 35.00 & 15.00 \\
P2B1 & 98.00 & -- & 0.30 & 1.40 & 0.30 \\
P5B1 & 95.00 & -- & 0.75 & 3.50 & 0.75 \\
P10B1 & 90.00 & -- & 1.50 & 7.00 & 1.50 \\
P15B1 & 85.00 & -- & 2.25 & 10.50 & 2.25 \\
P2B2 & 98.70 & -- & 0.30 & 0.70 & 0.30 \\
P5B2 & 96.75 & -- & 0.75 & 1.75 & 0.75 \\
P10B2 & 93.50 & -- & 1.50 & 3.50 & 1.50 \\
P15B2 & 90.25 & -- & 2.25 & 5.25 & 2.25 \\
M2B1 & -- & 98.00 & 0.30 & 1.40 & 0.30 \\
M5B1 & -- & 95.00 & 0.75 & 3.50 & 0.75 \\
M10B1 & -- & 90.00 & 1.50 & 7.00 & 1.50 \\
M2B2 & 0.70 & 98.00 & 0.30 & 0.70 & 0.30 \\
M5B2 & 1.75 & 95.00 & 0.75 & 1.75 & 0.75 \\
M10B2 & 3.50 & 90.00 & 1.50 & 3.50 & 1.50 \\
M15B2 & 5.25 & 85.00 & 2.25 & 5.25 & 2.25 \\
\hline
\end{tabular}


Table 3. Parameters derived from Gieseler test.

\begin{tabular}{llllll}
\hline Sample & $\operatorname{Ts}\left({ }^{\circ} \mathrm{C}\right)$ & $\operatorname{Tf}\left({ }^{\circ} \mathrm{C}\right)$ & $\operatorname{Tr}\left({ }^{\circ} \mathrm{C}\right)$ & $\operatorname{Tr}-\operatorname{Ts}\left({ }^{\circ} \mathrm{C}\right)$ & $\mathrm{MF}(\mathrm{ddpm})$ \\
\hline $\mathrm{P}$ & 405 & 462 & 500 & 95 & 1313 \\
P2B1 & 402 & 459 & 498 & 96 & 1346 \\
P5B1 & 405 & 456 & 498 & 93 & 1156 \\
P10B1 & 405 & 459 & 498 & 93 & 858 \\
P15B1 & 408 & 459 & 500 & 92 & 666 \\
P2B2 & 401 & 462 & 499 & 98 & 1219 \\
P5B2 & 401 & 457 & 497 & 96 & 1151 \\
P10B2 & 403 & 463 & 499 & 96 & 987 \\
P15B2 & 406 & 461 & 500 & 94 & 700 \\
M & 405 & 454 & 486 & 81 & 896 \\
M2B1 & 407 & 452 & 488 & 81 & 707 \\
M5B1 & 403 & 454 & 490 & 87 & 689 \\
M10B1 & 400 & 451 & 486 & 86 & 564 \\
M15B1 & 403 & 454 & 486 & 83 & 286 \\
M2B2 & 399 & 453 & 489 & 90 & 835 \\
M5B2 & 404 & 452 & 488 & 84 & 652 \\
M10B2 & 402 & 450 & 486 & 84 & 557 \\
M15B2 & 407 & 455 & 488 & 81 & 408 \\
\hline
\end{tabular}


Table 4. Particle size of the materials.

\begin{tabular}{lcccc}
\hline & $\mathrm{P}$ & $\mathrm{M}$ & $\mathrm{K}$ & $\mathrm{SC1}$ \\
\hline$<3 \mathrm{~mm} \mathrm{( \% )}$ & 86.0 & 75.5 & 89.8 & 97.4 \\
$2-3 \mathrm{~mm} \mathrm{( \% )}$ & 13.0 & 13.6 & 16.4 & 1.0 \\
$1-2 \mathrm{~mm} \mathrm{( \% )}$ & 19.56 & 17.7 & 18.9 & 1.6 \\
$0.5-1 \mathrm{~mm} \mathrm{( \% )}$ & 17.9 & 14.0 & 19.78 & 8.4 \\
$<0.5 \mathrm{~mm} \mathrm{( \% )}$ & 35.5 & 30.2 & 34.7 & 86.3 \\
\hline
\end{tabular}


Table 5. Comparison between porosity characteristics of cokes produced via partial briquetting and direct addition. Coal $\mathrm{P}$.

\begin{tabular}{lccccc}
\hline Sample & $\begin{array}{c}\rho_{\mathrm{He}} \\
\left(\mathrm{cm}^{3} / \mathrm{g}\right)\end{array}$ & $\begin{array}{c}\rho_{\mathrm{H} 2 \mathrm{O}} \\
\left(\mathrm{cm}^{3} / \mathrm{g}\right)\end{array}$ & $\begin{array}{c}\rho_{\mathrm{Hg}} \\
\left(\mathrm{cm}^{3} / \mathrm{g}\right)\end{array}$ & $\varepsilon(\%)$ & $\varepsilon<12 \mu \mathrm{m}(\%)$ \\
\hline $\mathrm{P}$ & 1.852 & 0.879 & 1.516 & 53 & 18 \\
P10B1 & 1.846 & 0.886 & 1.518 & 52 & 18 \\
P10B1 D & 1.875 & 0.859 & 1.564 & 54 & 17 \\
P15B1 & 1.917 & 0.874 & 1.450 & 54 & 24 \\
P15B1 D & 1.875 & 0.856 & 1.468 & 54 & 22 \\
P10B2 & 1.848 & 0.913 & 1.493 & 51 & 19 \\
P10B2 D & 1.883 & 0.878 & 1.487 & 53 & 21 \\
P15B2 & 1.907 & 0.936 & 1.429 & 51 & 25 \\
P15B2 D & 1.911 & 0.882 & 1.477 & 54 & 23 \\
\hline
\end{tabular}


Table 6. Analysis of ash composition.

\begin{tabular}{lcccccccccc}
\hline & $\begin{array}{c}\mathrm{SiO}_{2} \\
(w t . \%)\end{array}$ & $\begin{array}{c}\mathrm{Al}_{2} \mathrm{O}_{3} \\
(w t . \%)\end{array}$ & $\begin{array}{c}\mathrm{Fe}_{2} \mathrm{O}_{3} \\
(w t . \%)\end{array}$ & $\begin{array}{c}\mathrm{MgO} \\
(w t . \%)\end{array}$ & $\begin{array}{c}\mathrm{CaO} \\
(w t . \%)\end{array}$ & $\begin{array}{c}\mathrm{Na}_{2} \mathrm{O} \\
(w t . \%)\end{array}$ & $\begin{array}{c}\mathrm{K}_{2} \mathrm{O} \\
(w t . \%)\end{array}$ & $\begin{array}{c}\mathrm{TiO}_{2} \\
(w t . \%)\end{array}$ & $\begin{array}{c}\mathrm{P}_{2} \mathrm{O}_{5} \\
(w t . \%)\end{array}$ & $\mathrm{Al}$ \\
\hline $\mathrm{M}$ & 50.03 & 34.99 & 7.31 & 0.56 & 2.31 & 0.42 & 0.43 & 1.73 & 0.92 & 1.64 \\
$95 \mathrm{M}+5 \mathrm{~B} 1$ & 50.77 & 35.47 & 5.54 & 0.55 & 2.76 & 0.35 & 0.45 & 1.51 & 0.84 & 1.38 \\
$90 \mathrm{M}+10 \mathrm{~B} 1$ & 50.55 & 35.31 & 6.58 & 0.56 & 2.26 & 0.43 & 0.41 & 1.60 & 1.05 & 1.44 \\
$95 \mathrm{M}+5 \mathrm{~B} 2$ & 50.40 & 35.62 & 6.19 & 0.57 & 2.30 & 0.38 & 0.47 & 1.560 & 0.90 & 1.43 \\
$90 \mathrm{M}+10 \mathrm{~B} 2$ & 50.29 & 34.70 & 7.71 & 0.58 & 1.99 & 0.43 & 0.60 & 1.616 & 0.87 & 1.61 \\
$85 \mathrm{M}+15 \mathrm{~B} 2$ & 48.61 & 30.75 & 10.85 & 0.58 & 3.37 & 0.40 & 0.58 & 1.61 & 0.83 & 2.36 \\
$\mathrm{P}$ & 50.36 & 27.45 & 12.45 & 1.35 & 2.39 & 0.43 & 2.97 & 1.30 & 0.25 & 2.69 \\
$95 \mathrm{P}+5 \mathrm{~B} 1$ & 51.45 & 26.87 & 11.86 & 1.35 & 2.29 & 0.43 & 3.05 & 1.327 & 0.188 & 2.53 \\
$90 \mathrm{P}+10 \mathrm{~B} 1$ & 51.12 & 27.18 & 11.29 & 1.38 & 2.56 & 0.40 & 3.10 & 1.26 & 0.24 & 2.46 \\
$85 \mathrm{P}+15 \mathrm{~B} 1$ & 47.28 & 26.02 & 16.06 & 1.33 & 3.76 & 0.45 & 2.70 & 1.19 & 0.23 & 3.34 \\
$95 \mathrm{P}+5 \mathrm{~B} 2$ & 50.99 & 26.57 & 12.05 & 1.35 & 2.64 & 0.39 & 2.91 & 1.24 & 0.20 & 2.62 \\
$90 \mathrm{P}+10 \mathrm{~B} 2$ & 50.12 & 26.05 & 12.64 & 1.35 & 3.22 & 0.43 & 2.81 & 1.21 & 0.22 & 2.77 \\
85P+15B2 & 48.96 & 23.57 & 16.50 & 1.17 & 3.47 & 0.38 & 2.33 & 1.06 & 0.22 & 3.34 \\
\hline
\end{tabular}




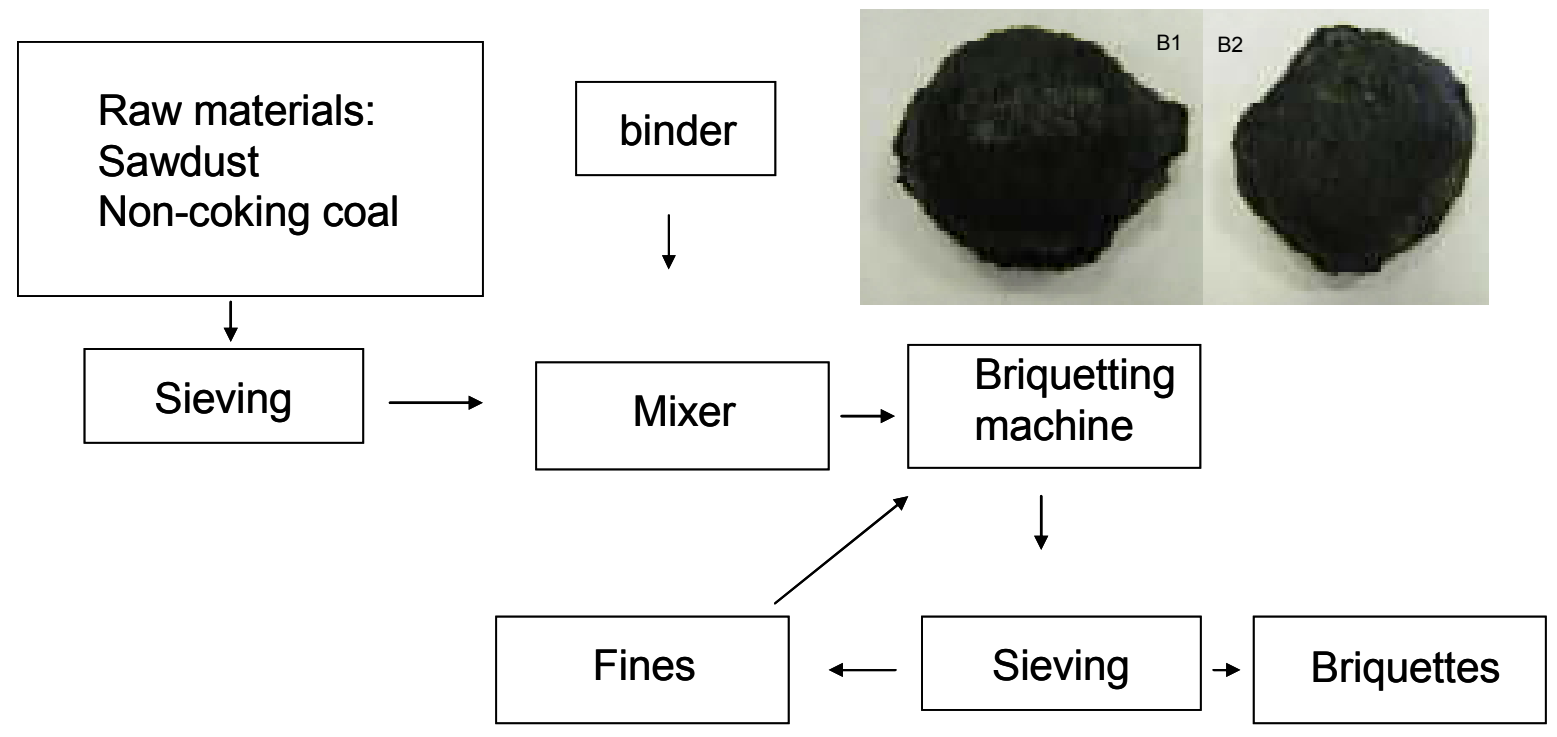

Figure 1. Diagram of the procedure used to produce briquettes and photograph of briquettes obtained. 

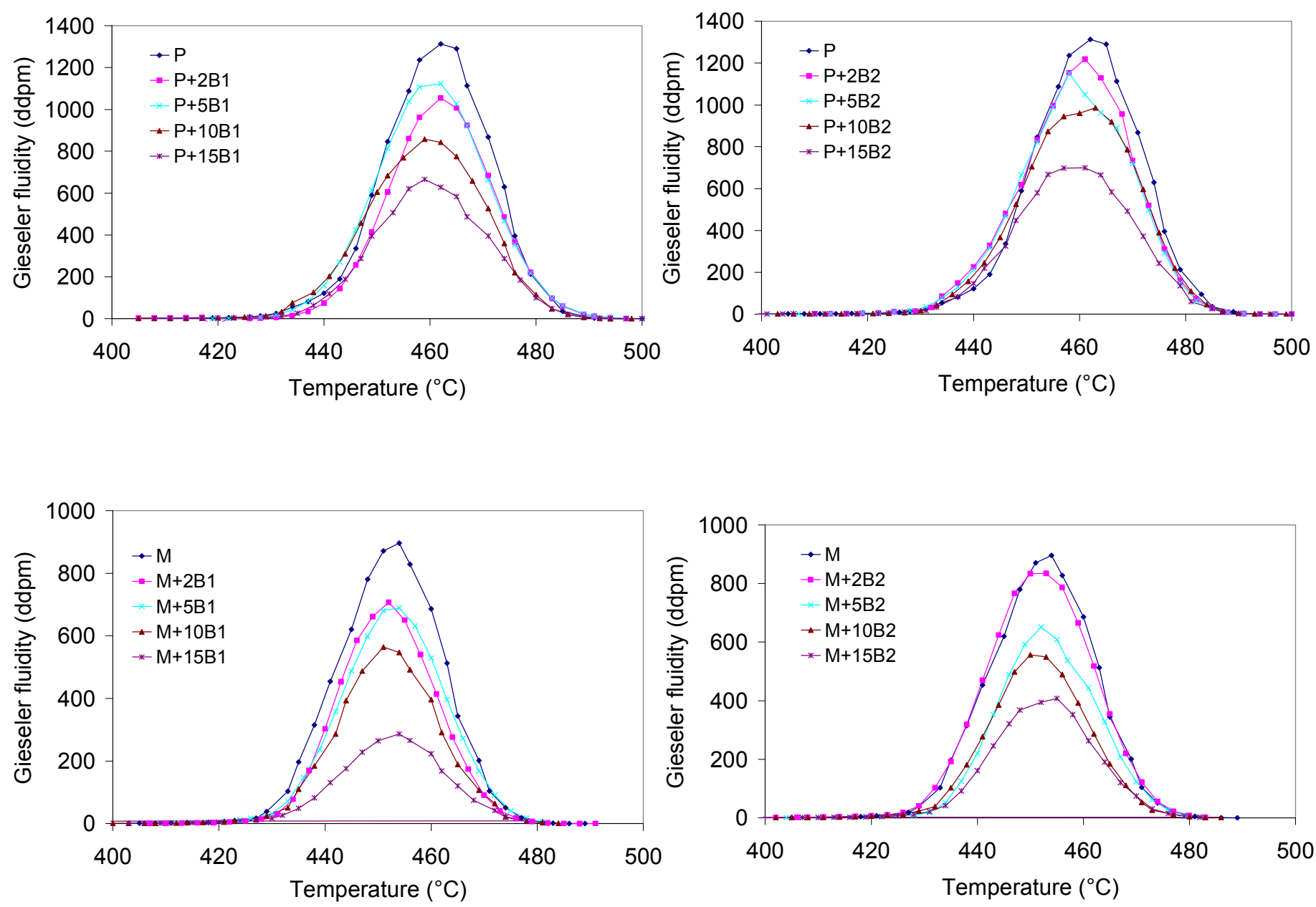

Figure 2. Gieseler fluidity curves of coal $\mathrm{P}$ and $\mathrm{M}$ with addition of various amounts of briquettes B1 and B2. 


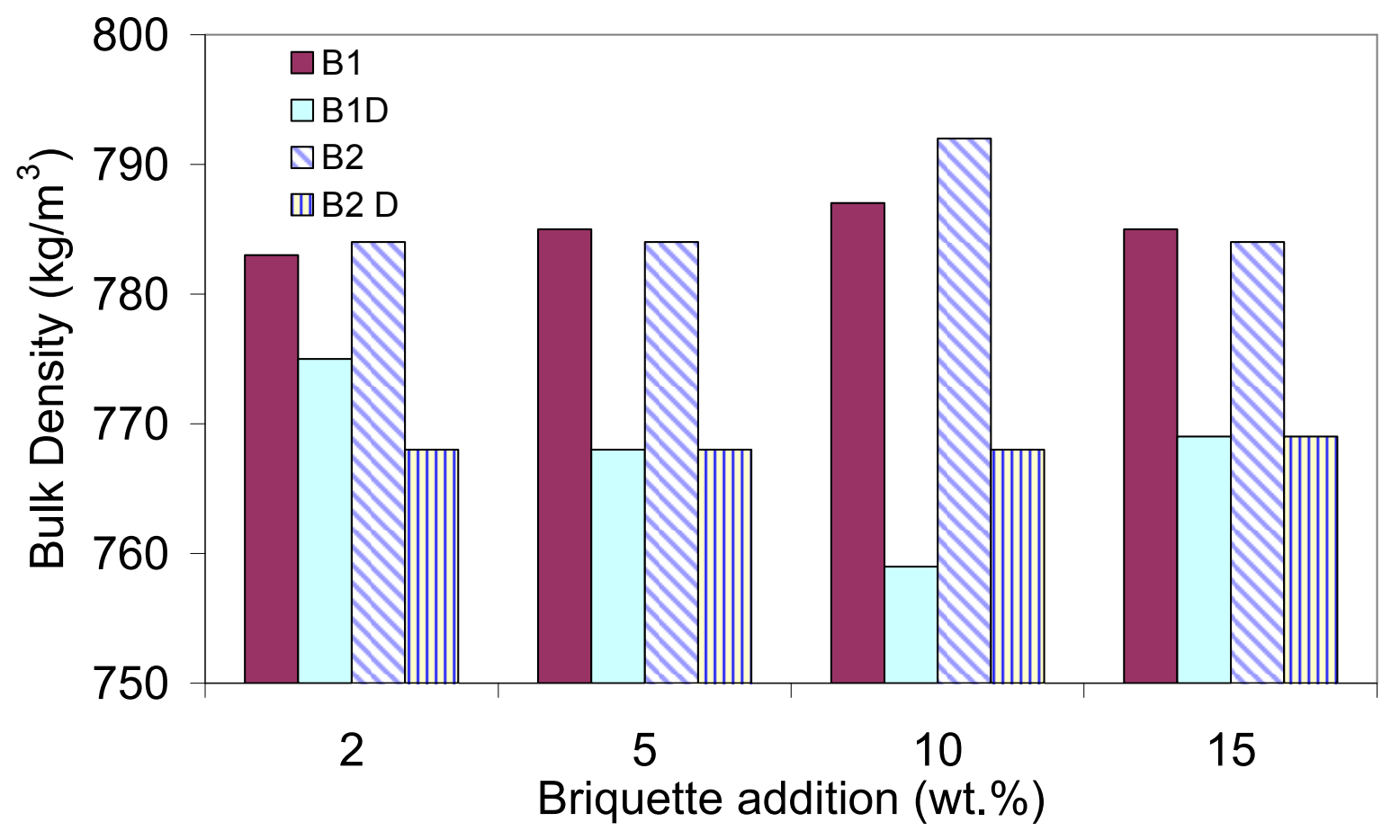

Figure 3. Variation of bulk density of the charge due to partial briquetting. Coal P. 


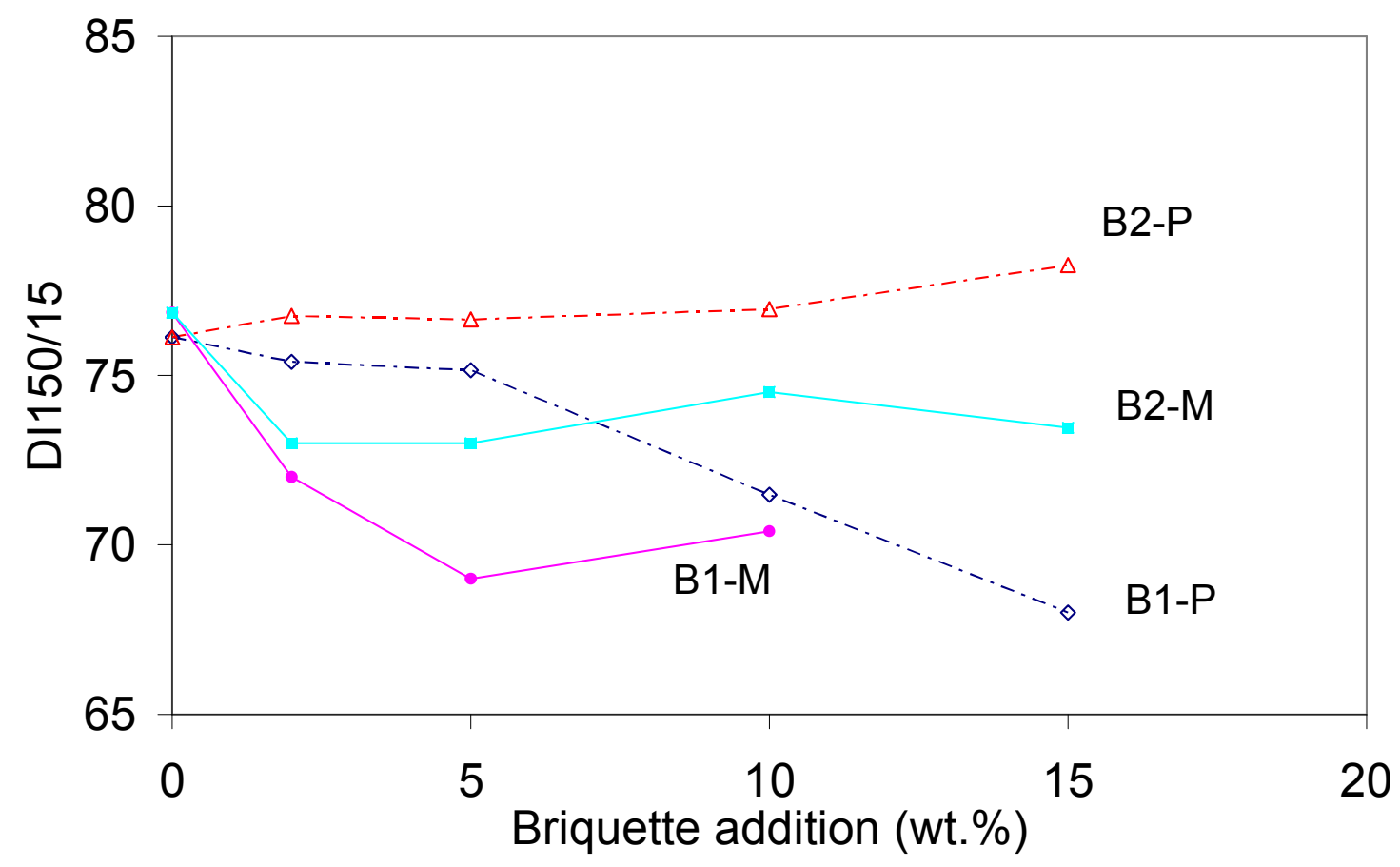

Figure 4. Influence of briquette addition on coke mechanical strength. 

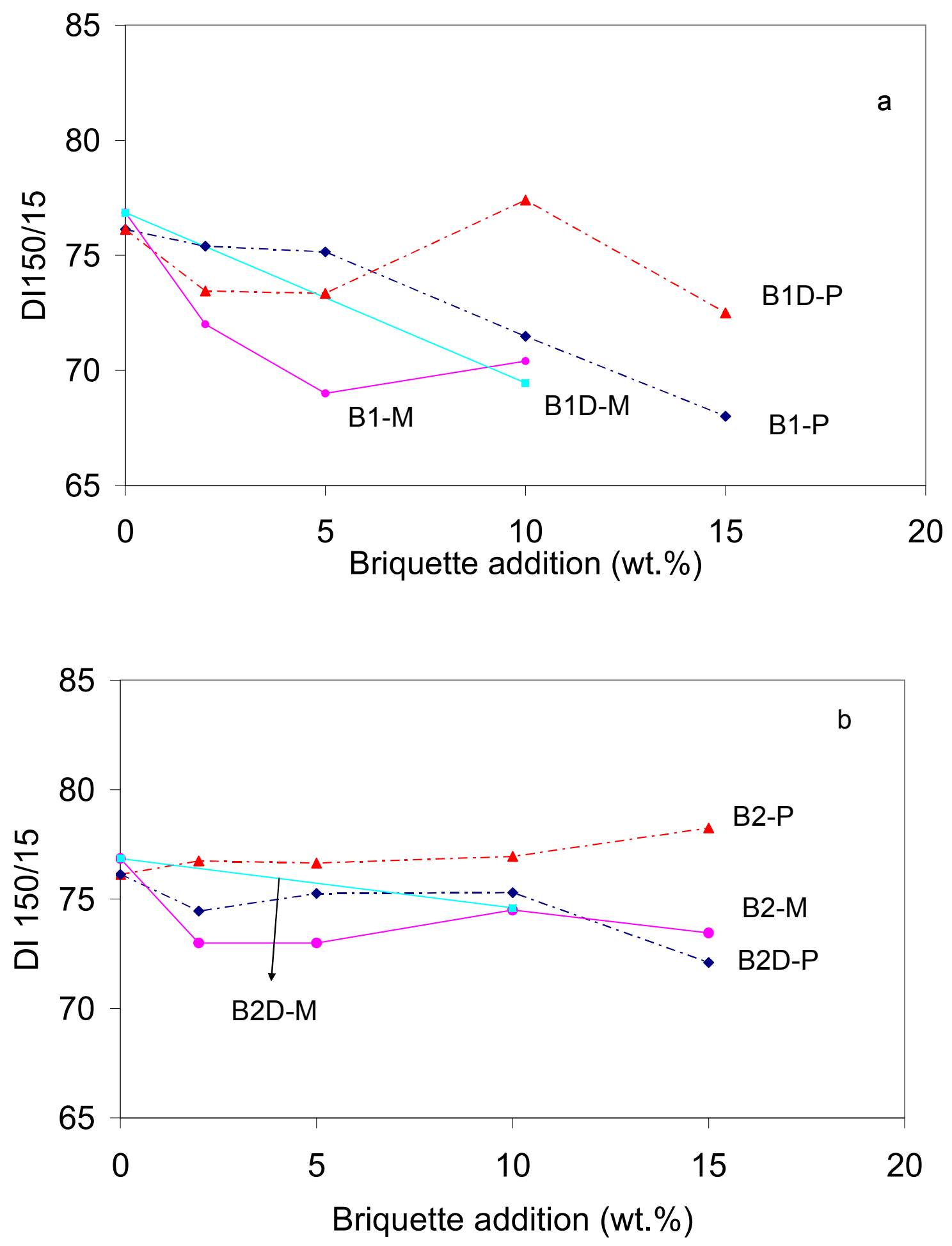

Figure 5. Comparison between the mechanical strength of cokes produced with direct addition and partial briquetting. 

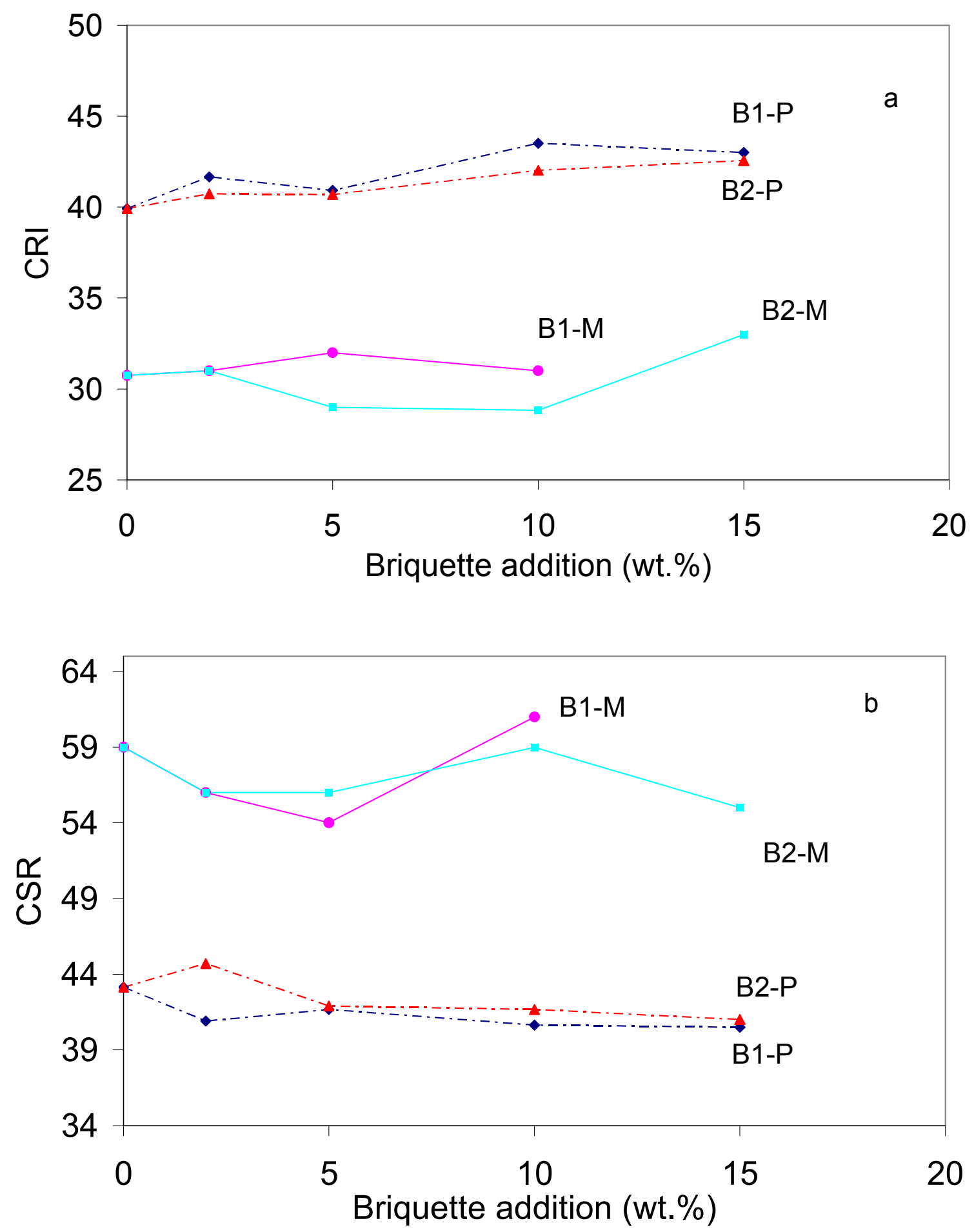

Figure 6. Effect of composition of briquettes on CRI and CSR indices of cokes from coals $\mathrm{P}$ and $\mathrm{M}$ with the addition of briquettes $\mathrm{B} 1$ and $\mathrm{B} 2$. 

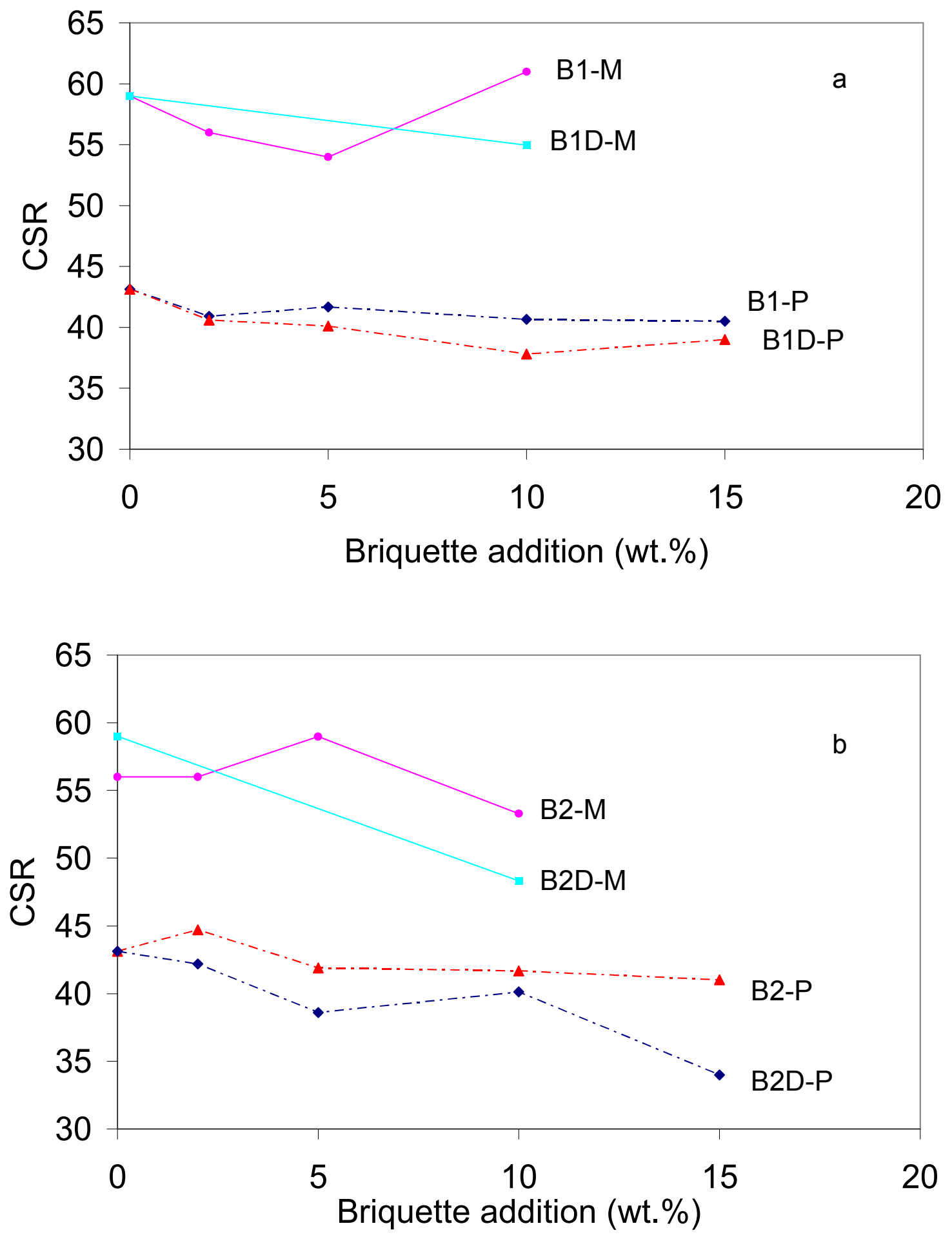

Figure 7. Effect of densification on the quality of cokes produced. 